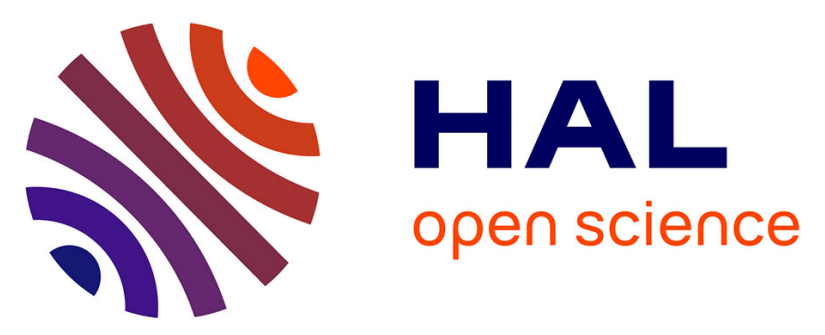

\title{
Automatic detection and discrimination of volcanic tremors and tectonic earthquakes: An application to Ambrym volcano, Vanuatu
}

\author{
Daniel Rouland, Denis Legrand, Mikhail Zhizhin, Sylvie Vergniolle
}

\section{- To cite this version:}

Daniel Rouland, Denis Legrand, Mikhail Zhizhin, Sylvie Vergniolle. Automatic detection and discrimination of volcanic tremors and tectonic earthquakes: An application to Ambrym volcano, Vanuatu. Journal of Volcanology and Geothermal Research, 2009, 181 (3-4), pp.196-206. 10.1016/j.jvolgeores.2009.01.019 . hal-03280964

\section{HAL Id: hal-03280964 https://hal.science/hal-03280964}

Submitted on 7 Jul 2021

HAL is a multi-disciplinary open access archive for the deposit and dissemination of scientific research documents, whether they are published or not. The documents may come from teaching and research institutions in France or abroad, or from public or private research centers.
L'archive ouverte pluridisciplinaire HAL, est destinée au dépôt et à la diffusion de documents scientifiques de niveau recherche, publiés ou non, émanant des établissements d'enseignement et de recherche français ou étrangers, des laboratoires publics ou privés. 


\section{Accepted Manuscript}

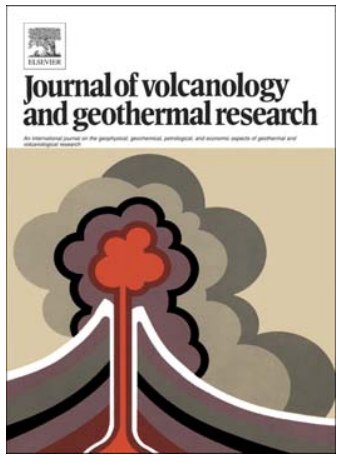

Automatic Detection and Discrimination of Volcanic Tremors and Tectonic Earthquakes : An Application to Ambrym Volcano, Vanuatu

Daniel Rouland, Denis Legrand, Mikhail Zhizhin, Sylvie Vergniolle

PII: S0377-0273(09)00035-3

DOI: doi: 10.1016/j.jvolgeores.2009.01.019

Reference: $\quad$ VOLGEO 4244

To appear in: Journal of Volcanology and Geothermal Research

Received date: 19 December 2008

Accepted date: 9 January 2009

Please cite this article as: Rouland, Daniel, Legrand, Denis, Zhizhin, Mikhail, Vergniolle, Sylvie, Automatic Detection and Discrimination of Volcanic Tremors and Tectonic Earthquakes : An Application to Ambrym Volcano, Vanuatu, Journal of Volcanology and Geothermal Research (2009), doi: 10.1016/j.jvolgeores.2009.01.019

This is a PDF file of an unedited manuscript that has been accepted for publication. As a service to our customers we are providing this early version of the manuscript. The manuscript will undergo copyediting, typesetting, and review of the resulting proof before it is published in its final form. Please note that during the production process errors may be discovered which could affect the content, and all legal disclaimers that apply to the journal pertain. 


\title{
Automatic Detection and Discrimination of Volcanic Tremors and Tectonic Earthquakes : An Application to Ambrym Volcano,
} 5 Vanuatu

Daniel Rouland $^{(1)}$, Denis Legrand ${ }^{(2)}$, Mikhail Zhizhin ${ }^{(3)}$ and Sylvie Vergniolle ${ }^{(4)}$

(1) Ecole et Observatoire des Sciences de la Terre, UMR 7516 ; 5, rue Descartes, 67084 Strasbourg, France

(2) Universidad de Chile, Departamento de Geofisica, Blanco Encalada 2002, Santiago, Chile. Now at : UNAM, Instituto de Geofisica, Departamento de Vulcanologia, Mexico D.F.

(3) Institute of Physics of the Earth, Russian Academy of Sciences, Moscow, Russia

(4) Institut de Physique du Globe de Paris, CNRS and Université de Paris 7, 4, place Jussieu, 75252 Paris cedex O5, France

\begin{abstract}
An algorithm of automatic detection and discrimination of volcanic tremors, defined as events containing only P-type wave, and tectonic earthquakes, containing both P- and S-
\end{abstract}


25 waves, is applied on data recorded on a 3-component STS-2 broad-band seismometer, installed from July to November 2000 at Ambrym volcano, Vanuatu. The algorithm consists of detecting P-waves and, if any, S-waves according to a modified version (Zhizhin et al., 2006) of the Component Energy Comparison Method (CECM) proposed by Nagano et al. (1989). The duration and maximum amplitude are automatically measured for each volcanic

30 tremor and for each tectonic earthquake with corresponding duration- and amplitudemagnitudes. During the four-and-half months of observation, 1959 local and regional tectonic earthquakes with epicentral distances (estimated from S-P interval time) ranging from a few kilometres to about $800 \mathrm{~km}$, and 14942 volcanic tremors with duration ranging from 10 to 2000 seconds, have been detected. The Gutenberg and Richter laws of tectonic earthquakes

35 and volcanic tremors are examined according to their duration- and amplitude- magnitudes, and completeness of the corresponding catalogues is studied. The observations on the coherence of some long duration volcanic tremors, which display four different intermittencies $(77+/-17 \mathrm{~min}, 165+/-10 \mathrm{~min}, 565+/-50 \mathrm{~min}, 1065+/-50 \mathrm{~min})$, are interpreted as different types of degassing.

Key words: automatic detector and discriminator, Ambrym volcano, long duration tremors

\section{Introduction}

Numerous event-detection schemes have been developed using single-station, vertical component seismic data. Those are effective in detecting teleseismic $\mathrm{P}$ phases, but their efficiency decreases for regional and local events due to lower incidence angles of the Pwave at short epicentral distances. Magotra et al. (1989) underlines at first the advantage to 
50 use the horizontal components to outperform a single-channel detector, and developed a detection scheme working in a manner similar to beam steering. Ohrnberger (2001) has applied the Hidden Markov Models for discrimination of volcanic tremors in a vertical component of the continuous seismic record. The use of 3-component data became prevalent in the 90 's. As the beginning of volcanic tremors is generally weak and emergent, automatic

55 detection must be strongly reinforced by analysing three-component records. A modified version of the Component Energy Comparison Method (CECM) developed by Nagano et al. (1989) was first proposed by Zhizhin et al. (2006), and is further updated in this paper in order to discriminate volcanic tremors from tectonic earthquakes.

60 The code consists in detecting P-waves and, if any, S-waves. If P- and S-waves are detected, the corresponding signal is identified as a tectonic event (which may eventually be a volcano-tectonic event). If no S-wave has been detected, the event is labelled as a volcanic tremor. The present study deals with the analysis of finite-duration signals recorded at Ambrym volcano, Vanuatu, on a 3-component STS-2 seismometer, in the 3-9 Hz frequency

65 domain, using this automatic detection algorithm. Additional processing is incorporated to automatically calculate basic source parameters, such as duration- and amplitude-magnitudes. The frequency-size distribution is then worked out from these automatic determinations of both volcanic tremors and tectonic earthquakes.

\section{Ambrym volcano and the July-November 2000 seismic experiment}

Ambrym volcano (Vanuatu Archipelago), located at $168.1^{\circ} \mathrm{E} ; 16.3^{\circ} \mathrm{S}$, is a $35 \times 50 \mathrm{~km}$ wide basaltic volcano, rising about $1800 \mathrm{~m}$ from the adjacent ocean floor (Fig. 1). Nearly $800 \mathrm{~m}$ above sea level, the edifice is truncated by a $12 \mathrm{~km}$-diameter caldera. Details on the Ambrym 
75 volcano structure, the historical eruptions and the time- frequency analysis of the continuous seismic data (short-period volcanic signals and very long period tremors) has already been discussed (Carniel et al., 2003; Legrand et al., 2005). Since the 1988-89 eruption, which produced extensive lava flows on the caldera floor, two lava lakes are observed inside Benbow and Marum craters. A third one, called Niri Mbwelesu Tatem, the smallest and 80 newest, is present on the flank of the Marum crater. Large bubbles, a few meters in diameter, are quite often seen and heard bursting at the surface, such as on August 71997 at Niri-Mbwelesu-Tatem (Fig.2, P Vetsch, pers. comm. and Steven Clegg, Kelby Hicks, http://www.volcan.org, Global Volcanism Program: http://www.volcano.si.edu).

85 During the July-November 2000 experiment, two seismic sensors (a vertical short-period Mark Product L4C and a 3-component Streckeisen STS-2 broad-band seismometer) have been deployed on Ambrym volcano. The short period instrument $\left(16.257^{\circ} \mathrm{S}, 168.108^{\circ} \mathrm{E}\right)$ was installed near the eastern rim of Benbow crater (Fig.1) and operated from 15 July to 11 August 2000 , while the broad-band STS-2 seismometer $\left(16.326^{\circ} \mathrm{S}\right.$ and $\left.168.058^{\circ} \mathrm{E}\right)$ was 90 installed near Lalinda village (Fig.1) on the southwestern flank of the main cone, at about 9 $\mathrm{km}$ from the Benbow crater and operated from 14 July to 26 November 2000. Both seismometers were connected to a GEOSTAR 16-bit data acquisition system. Continuous signals were sampled at a $75 \mathrm{~Hz}$ rate, the GPS-time being recorded on a separate channel. The complete data set was stored on a $2 \mathrm{~Gb}$ hard disk, allowing an independent, continuous 95 acquisition for about 4.5 months. During the 137-day data field acquisition, only 55 hours (9 November late to 11 November early) have been lost for the broad-band instrument, due to power-supply problems. 
Since the volcanic activity of Ambrym mainly consists in the bursting of large bubbles, we expect that most of volcanic signals will be related to the rise and the bursts of these bubbles acting as pressure sources. Hence the degassing will solely induce P-waves at the source

105 before being potentially converted, called here volcanic tremors. In order to automatically discriminate these volcanic tremors from tectonic earthquakes, an algorithm, further called Pand S-wave detector, has been developed. This algorithm is based on the detection of Pwaves and, if any, S-waves according to a modified version (Zhizhin et al., 2006) of the Component Energy Comparison Method (CECM) proposed by Nagano et al. (1989). The

110 candidate events are defined by the signal-to-noise ratio (SNR) $5 \mathrm{~dB}$ threshold with short gaps $(<20$ s) removed by closing operator from mathematical morphology (Serra, 1982). If a signal of P-wave type is found near the rise of SNR together with an S-wave, the detected signal is considered as a tectonic earthquake; if no S-wave is detected, the signal is interpreted as a volcanic tremor. In the first case, searching for the arrival time of S-wave is

115 done by a statistical segmentation of the amplitude distributions before and after S-arrival. An estimation of the signal duration is obtained from either the P-arrival or the SNR rise until the SNR decays below the same threshold.

\section{P- and S-wave detector}

In order to obtain a robust and sensitive P-wave detector, several different methods have been tried, including the STA/LTA detector (Vanderbulk et al., 1965), the linear polarization detector, and the multi-resolution detector using wavelet-transform (Anant and Dowla, 1997). The best results are obtained when using a modified version of the Component Energy 
125 Comparison Method (CECM), proposed, for automatic detection of P-arrivals, in Nagano et al. (1989), for the location of acoustic emissions.

The simple idea behind CECM is that in any P-wave, the 3-D particle motion occurs along one direction, and there is no particle motion in the plane perpendicular to this direction.

130 Thus, a correlation of energy dissipating in the direction of the P-wave motion with the energy dissipated in other directions will be close to zero. On the other hand, in case of random motion in seismic noise we have, on average, the same amount of energy dissipated in all directions.

135 If we assume that the seismic noise is a multivariate Wiener stochastic process, then the energy dissipated in each channel will be proportional to the recording time, $E_{x}(t) \sim t$ (Wentzell, 1981). Thus, the energy will be correlated between channels. Deterministic component in the stochastic signal (in our case the P-wave arrival) will temporarily destroy the established cross-channel correlation.

140

In our version of the CECM algorithm, we correlate the energy dissipated in a moving time window $\Delta T=25 \mathrm{sec}$ between the three components of the seismic record. The total energy dissipated in each direction (e.g. along discrete time channel $x(i)$ ) is defined by:

145

$E_{x}(t)=\sum_{i=1}^{t} x^{2}(i), \quad t>1$

The choice of the initial time $t=1$ may seem arbitrary: the only requirement is that it is "fixed" long before the P-wave onset at each hour boundary. To be less sensitive to the 
direction of the P-wave arrival, we analyze a product of the energy correlation coefficients

150 between $x-z$ and $y-z$ channels ( $z$ is the vertical component of the motion; $x$ and $y$ are in the horizontal plane; $x$ is North-South; $y$ is West-East):

$$
R(t, \Delta T)=R_{x z}(t, \Delta T) R_{y z}(t, \Delta T)
$$

155 where the energy correlation between $x-z$ channels is defined by

$$
R_{x z}(t, \Delta T)=\frac{\sum_{i=t}^{t+\Delta T} E_{x}(i) E_{z}(i)}{\sqrt{\sum_{i=t}^{t+\Delta T} E_{x}^{2}(i) \sum_{i=t}^{t+\Delta T} E_{z}^{2}(i)}},
$$

and $R_{y z}(t, T)$ is defined by the same formula by changing $x$ into $y$. The P-wave arrival $t_{0}$ is

160 preliminarily determined as the time at which the coefficient $R(t, T)$ reaches a local minimum, as shown in Fig. 3. To reduce the number of false detections, we introduce an experimentally determined threshold for the candidate local minima values: $R(t, T) \leq 0.6$.

The P-wave arrival time $t_{p}$ is more precisely determined by fitting a parabola to several

165 values of $R(t, T)$ before $t_{0}$ and finding the time when the fitted parabola intersects time axis. Hence we pick the first statistical evidence of the P-arrival before the well-developed wavetrain at $t_{0}$. 
Our S-wave detector is based on two assumptions: first, the probability density functions for

170 the distribution of seismic signal amplitudes $a(t)$ in the Hilbert transform envelopes of the P- and S-wave trains $p_{p}(a(t))$ and $p_{s}(a(t))$ are normal with significantly different means

but similar variances $N\left(\mu_{p}, \sigma\right)$ and $N\left(\mu_{s}, \sigma\right)$; second, the signals within each of the wavetrains can be considered as quasi-stationary (see Nagano et al., 1989). Then arrival time $t_{s}$ of

175 the S-wave will divide the signal in the time window between P-arrival $t_{p}$ and maximum degree of polarization $t_{\max }$ (which for regional seismograms occurs within the S-wave) into two homogeneous segments $t_{p} \leq t_{s} \leq t_{\max }$ with the likelihood

$$
L\left(t_{s}\right)=\log \prod_{i=t_{p}}^{t_{s}} p_{p}\left(a\left(t_{i}\right)\right) \prod_{i=t_{s}+1}^{t_{\max }} p_{s}\left(a\left(t_{i}\right)\right)
$$

180

For normal distribution functions $p_{p}(a(t))$ and $p_{s}(a(t))$, the likelihood formula will be

$$
L\left(t_{s}\right) \approx-\frac{t_{s}-t_{p}}{2} \log \frac{1}{t_{s}-t_{p}} \sum_{i=1}^{t_{s}}\left[a\left(t_{i}\right)-\mu_{p}\right]^{2}-\frac{t_{\max }-t_{s}}{2} \log \frac{1}{t_{\max }-t_{s}} \sum_{i=t_{s}}^{t_{\max }}\left[a\left(t_{i}\right)-\mu_{s}\right]^{2}
$$

185 where

$$
a\left(t_{i}\right)=\sqrt{x(t)^{2}+y(t)^{2}+z(t)^{2}}, \quad \mu_{p}=\frac{1}{t_{s}-t_{p}} \sum_{i=1}^{t_{s}} a\left(t_{i}\right), \quad \mu_{s}=\frac{1}{t_{\max }-t_{s}} \sum_{i=t_{s}}^{t_{\max }} a\left(t_{i}\right) .
$$


The optimal S-wave arrival time $t_{s}$ should maximize the value of the likelihood function $L\left(t_{s}\right)$

190 (Fig. 3).

Tremors discrimination

Following Nagano et al. (1989), we examine the SNR in a time window $T$ centred at time $t$ 195 and defined by the formula

$$
\operatorname{SNR}(t)=20 \log \left(P_{\text {signal }}(t) / P_{\text {noise }}(t)\right)
$$

where the average amplitudes of signal and noise are defined as

200

$$
\begin{aligned}
& P_{\text {signal }}(t)=\frac{1}{T} \sum_{i=t-T / 2}^{t+T / 2} \sqrt{x^{2}(i)+y^{2}(i)+z^{2}(i)}, \\
& P_{\text {noise }}(t)=\frac{1}{t} \sum_{i=t_{0}}^{t} \sqrt{x^{2}(i)+y^{2}(i)+z^{2}(i)}
\end{aligned}
$$

205 The arbitrary starting point $t_{0}$ used for accumulation of the average noise amplitude should be taken some time before the beginning of the tremor (we take $t_{0}$ at the hour boundary). A tremor is detected when its amplitude is above the noise level threshold $S N R(t)>5 \mathrm{~dB}$.

To remove small gaps in the tremor detection when the SNR is just around the threshold, we 210 apply a closing operator from mathematical morphology (Serra, 1982). It is a 1-D version of the, widely one used in image processing, composition of the basic morphological operators, 
dilation and erosion, both of them using the same structural element - a segment with fixed duration of $20 \mathrm{sec}$. As a result of the closing, any two detected tremors with a less-than-20sec time gap between them will be merged in a single tremor without gap.

The SNR threshold detection is usually good for detection of the beginning of the tremor, but it is biased by the embedded signal when used for detection of the tremor end. To estimate the tremor duration, we have to recalculate the SNR starting from the beginning of the tremor ( $t_{0}$ in Eq. 9 equals the current tremor start time). The "unbiased" tremor end is reached 220 when the noise level gets below the same threshold $S N R(t)<5 \mathrm{~dB}$

We use a simple discrimination rule between the tectonic earthquakes and volcanic tremors: if a signal of P-wave type is detected near the rise of SNR tremor (within $8 \mathrm{sec}$ ), the detected signal is considered as a tectonic earthquake; otherwise the signal is associated to a volcanic tremor.

\section{Data processing}

230 The permanent signal is generated by the superposition of the intrinsic volcanic and tectonic activity and the local (and regional) meteorological conditions. Hence, the data processing is strongly dependent on the choice of the frequency window. It has been shown that station noise levels strongly vary according to the frequency, and the local site effects, especially on an island like Ambrym. Stutzmann et al. (2000) show numerous observations of noise levels

235 in Geoscope stations. A minimum of the noise level is frequently observed at short periods, 
between $1.0 \mathrm{sec}$ and $0.10 \mathrm{sec}$, for stations located on islands or close to a coast, such as at stations PPT, French Polynesia, or KIP, Hawaii). Fig. 4 shows raw and filtered data for different fourth-order Butterworth band-pass filters, with a good resolution in the 3-9 and 3$18 \mathrm{~Hz}$ frequency band. A significant increase of SNR for both tremors and local (and

240 regional) earthquakes is also observed in these frequency domains. In the 9-27 Hz frequency range, numerous signals are generated by human near-activities and therefore we do not process the data in this frequency range. We have finally selected the fourth-order Butterworth 3-9Hz band-pass filter for the data processing: an example of half-a-day record (Fig. 5) clearly displays both regional tectonic earthquakes, identified on the local IRD

245 (Institut pour la Recherche et le Développement, Centre de Nouméa, Nouvelle Calédonie) earthquakes catalogue and volcanic tremors.

\section{Results}

250 During the 4.5 months of measurements, during which the volcano was relatively quiet, 1959 tectonic earthquakes with epicentral distances (estimated from S-P interval time) ranging from a few kilometres to about $800 \mathrm{~km}$ (but most of them with distances $<200 \mathrm{~km}$ ), have been detected, as well as 14942 volcanic tremors with duration ranging from 10 to 2000 seconds.

\section{Tectonic earthquakes}

We have removed 150 events from the initial set of the 1959 detected earthquakes because a visual inspection had shown that they mainly correspond to an identification of a PP-wave instead of an S-wave. Records from selected tectonic earthquakes are presented in Fig. 6, 
corresponding to two short-distance hypocenters (top), with an epicentral distance lower than $4 \mathrm{~km}$, and two other regional earthquakes (bottom) with respectively 34 and $67 \mathrm{~km}$ epicentral distances. In Fig. 7, the whole set of detected events is plotted in a chronological sequence according to their epicentral distances (in $\mathrm{km}$ ): each distance is roughly estimated (no

265 account of the depth of the event is taken) by multiplying by a factor of 8 the difference of the arrival times, in seconds, between S- and P- waves (this empirical formula being deduced from a standard crust model, e.g. Jeffreys and Bullen , 1935).

Most of the regional seismicity is well detected with this unique station. Three swarms of seismic activity corresponding to 3 large earthquakes which occurred in Vanuatu show up as dense dot clusters: the first swarm corresponds to the 9 August 2000, $\mathrm{Mw}=6.0$, earthquake which occurred at about $70 \mathrm{~km}$, northward, from the station. The second swarm corresponds to the 4 October $2000, \mathrm{Mw}=6.9$, earthquake located in the north-west direction from the station, at about $150 \mathrm{~km}$, and the third one corresponds to the 15 November 2000, Mw $=5.7$,

275 earthquake located off the coast of Espiritu-Santo Island, at a distance of about $250 \mathrm{~km}$. A persistent seismic activity is also observed following the 3 November $2000, \mathrm{mb}=4.9$, local event located off the coast of Ambrym at a distance of about $50 \mathrm{~km}$. The number of events at distances greater than $300 \mathrm{~km}$ decreases rapidly, partially due to the high-frequency range (3$9 \mathrm{~Hz}$ ) used for data filtering.

The cumulative number of the entire tectonic earthquakes displayed as a function of the amplitude-magnitude (Fig. 8) follows the Gutenberg-Richter law. Fig. 8 also shows that the catalogue is almost complete above local amplitude-magnitude 2.4. This supports the hypothesis that our code can automatically detect almost all the local and regional 
285 earthquakes. Obviously we don't take into account the largest events because of the short time duration of the survey.

In Fig. 9a, the cumulative number of the whole set of tectonic earthquakes is plotted according to their duration-magnitude and is very similar to that one displayed in Fig 8: this

290 means that for tectonic earthquakes the magnitudes calculated from the maximum amplitude or from the duration are almost equivalent. In Fig. 9b, we selected only the local events (at a distance less than $100 \mathrm{~km}$ ). Here again, the curve follows the Gutenberg-Richter law, which means that the catalogue is also complete for local earthquakes.

295 Hence, the cumulative number of tectonic events follows a Gutenberg-Richter law whatever the magnitude we use (amplitude or duration- magnitudes).

\section{Volcanic tremors}

30014942 volcanic tremors of duration greater than $10 \mathrm{~s}$ have been detected during the entire period of measurements. The cumulative numbers of volcanic tremors are discussed hereafter as a function of their duration-magnitude and of their relative amplitude-magnitude and compared to tectonic earthquakes. The log-log plot frequency-duration of tremor distribution (Fig. 10a) clearly shows two regimes, with a transition at duration of $100 \mathrm{sec}$

305 (Fig. 10a). The number of long duration $(>100 \mathrm{sec})$ tremors (hereafter called LDT) is much larger than those predicted by the extrapolation based on the distribution of the short duration $(<100 \mathrm{sec})$ tremors (hereafter called SDT). The deviation from the Gutenberg-Richter law of the volcanic tremors of duration greater than $100 \mathrm{sec}$ suggests that an additional mechanism is at work inside the volcanic edifice and might correspond to two different physical 
310 processes for example related to some cooling of the lava lake as observed at Kilauea (Chouet, 1979).

But if we consider now the amplitude instead of the duration (Fig 10b), the double slope of the Gutenberg-Richter observed on Fig 10a disappears. This suggests that no clear relation

315 exists between duration and amplitude for volcanic tremors as shown on Figure 11 and in contrast to tectonic events. The relation between amplitude and duration (Fig. 11) is not clear for SDT and small amplitudes ( $<100$ in relative amplitudes), whereas most of the LDTs have a quasi-constant amplitude. The number of tremors/day (the whole set with relative amplitude $>10$ ) and the number of tremors/day with duration $>100 \mathrm{sec}$ are displayed

320 in Figures $12 \mathrm{a}$ and $12 \mathrm{~b}$ respectively. We can see that the LDTs do not follow a regular time distribution (Fig. 12b) in contrast to the distribution of all tremors including SDTs (Fig. 12a), revealing one more time very particular physical processes for these LDTs that are not well understood. Therefore we analyze hereafter the tremors with respect to their duration magnitude instead of using the amplitude magnitude (several tremors have the same 325 amplitude with a completely different duration).

\section{Analysis of the long duration tremors (LDT):}

Numerous long duration tremors (LDT) are very well observed on some daily records of the

330 vertical component filtered between 3 and $9 \mathrm{~Hz}$ (Fig. 13). We observe that the quiescence time, here called intermittency, between two consecutive LDTs varies between two main values, around one and two hours. This intermittency of the total number of LDTs presents four distinct peaks (Fig. 14). The first one at $77+/-17 \mathrm{~min}$ is composed of three values, around 60, 85 and 95 min, whose differences may or may not be significant; the second one 
335 at $165+/-10 \mathrm{~min}$, the third one at $565+/-50 \mathrm{~min}$ and the fourth at $1065+/-50 \mathrm{~min}$. This shows that these LDTs have a tendency to occur regularly, with four different intermittencies, suggesting that the system must restore its energy before emitting new LDT. Hence the generation of LDTs seems to be quasi-periodic with four characteristic time scales. Furthermore, the four intermittencies are proportional, within the error bar, to the lowest intermittency of $77 \mathrm{~min}$ by a factor of $1,2,7$ and 13 respectively.

Our definition of a volcanic tremor as being a sole P-wave suggests looking for a mechanism related to a local source of pression. One obvious candidate on a basaltic volcano is related to gas because of the very compressible nature of the gas. Furthermore bursting bubbles have 345 already thought to be responsible for the tremor at Stromboli but they can also radiate significant amount of seismic and acoustic energy during explosions (Ripepe, 1996; Vergniolle and Brandeis, 1996; Chouet et al., 1999; 2003). The seismic energy at Stromboli is explained by the pressurisation of the volcanic conduit associated with the ascent of a slug (Chouet et al., 2003). Visual observations at Niri Mbwelsu Tatem of large bubbles bursting

350 while radiating sound waves (P Vetsch, pers. comm.; M Lardy, pers. comm.) indeed suggest associating the lowest intermittency of $77 \mathrm{~min}$ to the regular occurrence of large bubbles. Furthermore this intermittency is similar to that observed at the northeast vent at Stromboli (Ripepe, 1996; Vergniolle and Brandeis, 1996). Although, at Stromboli, the duration of explosions recorded on seismometers is usually shorter than 100 s (Chouet et al., 1999;

355 2003), a mechanism related to the ascent of a slug is also likely for explaining the long duration of the LDTs at Ambrym. It is then tempting to relate each of the three similar intermittencies, $60 \mathrm{~min}, 85 \mathrm{~min}$ and $95 \mathrm{~min}$, to the occurrence of large bubbles in each of the three lava lakes. Furthermore the proportionality of the four main intermittencies, $77 \mathrm{~min}$, 
$165 \mathrm{~min}, 565 \mathrm{~min}$ and $1065 \mathrm{~min}$ with the lowest one may point towards a mechanism more

360 widely related to degassing within a magma reservoir. Fig 15 shows the time distribution of LDTs as a function of amplitude (a) and duration (b). Despite the dispersion of the data, a delay of about thirteen days separate most of the bursts of LDTs, whose duration exceeds 100 s (Fig 15b). This time scale, although not as apparent on the time evolution of the amplitude (Fig 15a) could indicate that another characteristic time may also exist. But in the absence of

365 longer time series, the existence of intermittency at $13+/-2$ days is still not formally shown.

Since a sole three-component broadband seismometer has been installed, we cannot locate the source generating these tremors. Moreover, the particle motion associated with these LDTs is erratic and cannot be used for source location purposes. Nevertheless, we have to 370 mention that these LDTs are very well recorded by the vertical short period instrument installed on the rim of the Benbow's vent. For example, on $26^{\text {th }}$ July, an intense LDT's activity is observed both at Lalinda broad-band station and at the short-period station located on the rim itself. The sudden increase, limited in time to one day, of both signals may be associated to a strong reactivation of the lava lake.

\section{Analysis of short duration tremors (SDT) :}

The cumulative number of SDTs (duration between 10 and 100sec) has been shown on Figure 10a. The SDTs follow a classical Gutenberg-Richter law, both for duration-magnitude 380 (Fig 10a) and for amplitude-magnitude (Fig.10b). This was not the case for LDTs (Fig.10a) for which the source time function may be longer and more complex than that expected for a classical tectonic event controlled by a short and simple source time function. 


\section{Concluding comments}

We have developed a code to automatically discriminate tectonic earthquakes from volcanic tremors, both recorded on a volcano. The algorithm is applied to the seismic data collected during a four-and-a- half-month survey at Ambrym volcano (Vanuatu). We found that the Gutenberg-Richter law is satisfied for both the tectonic earthquakes and the volcanic tremors: this means that the physics generating these tectonic and volcanic events are auto-organized processes. It shows also that the code is efficient to select all the events and that very few may have been missed. This has been possible, despite the sole use of a single station, only because of the use of an automatic detection and discrimination code applied on a large amount of data.

The time series associated to LDT show the existence of four intermittencies, from one hour to less than a day: the one hour period could be related to the occurrence of large bubbles rising in the conduit and bursting at the vent, while the three others are likely to result from other degassing process within the magma reservoir.

\section{Acknowledgements}

We are very grateful to the people of Lalinda village, Vanuatu, for their help in the field operations, to M. Frogneux and the technical support of the Laboratory of Seismology, EOST, Strasbourg, France, the Department of Geology, Mines and Water Resources, Port Vila, Vanuatu, J.Ph. Caminade, from I.R.D, in place at Port Vila, who organized successfully the whole logistic of the survey and R. Carniel, D. Charlie, M. Fulle, D. Nakedau, M. 
Regnier and G. Roult who participated actively in the fieldwork or providing logistical help. DL thanks Fondecyt $\mathrm{N}^{\circ}$ 1061256. SV is grateful for the help of IPGP (BQR, contribution

410 number: 2371), INSU (ACI: contribution number: 409) and ANR. We thank Jean Bonnin and Roberto carniel whose critical remarks improve considerably the text and for their constructive evaluation of this manuscript and Bill McGuire who accepted the challenge for editing this article.

415

\section{References}

Carniel, R., Di Cecca, M., and Rouland, D., 2003. Ambrym, Vanuatu (July-August 2000):

420 Spectral and dynamical transitions on the hours-to-days timescale. J. Volcan. Geotherm. Res., $128,1-13$

Chouet, B., 1979. Sources of seismic events in the cooling lava lake of Kilauea Iki, Hawaii, J. Geophys. Res., 84, 2315--2330.

Chouet, B.A., G.Saccorotti, P.Dawson, M.Martini, R.Scarpa, G.De Luca, G.Milana and M.Cattaneo, Broadband measurements of the sources of explosions at Stromboli volcano, Italy, Geophys. Res. Lett., 26, 13, 1937--1940, 1999.

430 Chouet, B.A., P.A. Dawson, T. Ohminato, M.Martini, G.Saccorotti, F. Giudicepietro, G.De Luca, G.Milana and R.Scarpa, Source mechanisms of explosions at Stromboli volcano, Italy, 
determined from moment-tensor inversions of very-long-period data, J. Geophys. Res., 108, B1, 2019, ESE 7, 1-25, 2003.

435 Jeffreys, H. and K.E. Bullen ,1935. Times of transmission of earthquake waves, Bureau Central Séismologique International A, Fasc. 11, 202 pp.

Legrand, D., Rouland, D., Frogneux, M., Carniel R., Charley, D., Roult, G. and Robin C., 2005. Interpretation of Very Long Period Tremors at Ambrym volcano, Vanuatu, as quasi440 Static Displacement Field related to two distinct magmatic sources, Geophys. Res. Lett., 32, 6, L0631410.1029/2004GL021968

Magotra, N., Ahmed, N., Chael, E., 1987. Seismic event detection and source location using single-station (three-component) data, $B S S A, 77,958-971$

Nagano, K., H. Niitsuma, \& N. Chubachi, 1989. Automatic algorithm for triaxial hodogram source location in downhole acoustic emission measurement. Geophysics, 54, 4, 508-513

Ohrnberger, M., 2001. Seismic event detection and source location using single-station 450 (three-component) data, Ph.D. Thesis, Potsdam University, on line at http://opus.kobv.de/ubp/volltexte/2005/31/pdf/ohrnberg.pdf

Ripepe, M., 1996. Evidence for gas influence on volcanic seismic signals recorded at Stromboli, J. Volcanol. Geotherm. Res, . 70, 221-233.

Serra, J, 1982. Image Analysis and Mathematical Morphology, Academic Press, London. 
Stutzmann, E., Roult, G. and Astiz, L., 2000. Geoscope station noise levels, Bull. Seism. Soc. Am., 90, 3, 690-701.

460

Vanderkulk, W., Rosen, F. and Lorenz, S., Large aperature seismicarray signal processing study. IBM Final Report, ARPA Contract Number SD-296, 1965.

Vergniolle, S., and G. Brandeis, 1996. Strombolian explosions: A large bubble breaking at 465 the

surface of a lava column as a source of sound, J. Geophys. Res., 101, B9, 20,433-20,448.

Wentzell, 1981. A course in the theory of stochastic processes, Mc. Graw-Hill, NY.

470 Zhizhin, M., Rouland, D., Bonnin, J., Gvishiani, A., and Burtsev, A., 2006. Rapid estimation of earthquake source parameters from pattern analysis of waveforms recorded at a single 3component station, Bull. Seism. Soc. Am, 96, 6,2329-2347. 


\section{Figure captions}

Fig. 1. Ambrym volcano with the three main active vents, and overview (up right) of the seismicity (1993-1998) observed in New Hebrides Archipelago (blue, green and red dots correspond respectively to shallow, intermediate and deep earthquakes). The white triangle and the white circle represent respectively the broadband and the short period stations.

Fig. 2. Large bubbles, probably a few meters in diameter, quite often seen and heard bursting at the surface, such as on August 71997 at Niri Mbwelesu Tatem (Courtesy of P Vetsch). The depth of the lava lake is probably $140 \mathrm{~m}$ below the surface.

Fig. 3. Example of $\mathrm{P}$ and $\mathrm{S}$ detections:

top and $2^{\text {nd }}$ rows : vertical and transverse components with $\mathrm{P}$ and $\mathrm{S}$ arrival marks and amplitudes in $\mu / \mathrm{s}$, the transverse component evaluated using the NEIC location; $3^{\text {rd }}$ row : dimensionless P-wave CECM detector output with solid line for energy correlation

490 across the channels; candidate local minima marked by a star; SNR plotted with a dashed line; and threshold SNR sections marked as dotted segments;

bottom: dimensionless S-wave detector output.

Fig. 4. Examples of fourth-order Butterworth band-pass filtered seismic signals: each subset corresponds to 6 hours record: a) raw data, b) 0.2 to $2 \mathrm{~Hz}$ filtered data, c) 3 to $9 \mathrm{~Hz}$ filtered data and d) 3 to $18 \mathrm{~Hz}$ filtered data. Notice that the SNR increases drastically for a low-cut frequency greater than $2 \mathrm{~Hz}$. 
Fig. 5. Half-a-day seismic record showing different types of events and tremors. Each trace is

500 drawn with the same standard scale, this explaining some apparently-saturated signals.

Fig. 6. Example of records of very-near and near earthquakes detected, with values of parameters used in the processing. The green line on top (EW component) shows the CECM P-wave detector output. Its local minima within $5 \mathrm{~dB}$ SNR brackets (black) indicates the Pwave arrival. The next magenta mark is the S-wave arrival. The last magenta mark indicates the end of detected record used for the duration magnitude estimate. The magenta line of the median traces (NS component) depicts the S-wave detector likelihood.

Fig. 7. The whole set of detected events as a function of time.

Fig. 8. Cumulative number of the whole set of detected tectonic earthquakes as a function of the amplitude-magnitude. The amplitude-magnitude is calculated according to the law $\mathrm{M}=$ $\log (\mathrm{A} / \mathrm{T})_{\max }+1.66 \mathrm{D}+\mathrm{C}$ where $\mathrm{A}$ is the amplitude (in microns), $\mathrm{T}$ is the period (in second), $\mathrm{D}$ is the distance (in $\mathrm{km}$ ) and $\mathrm{C}$ is a constant determined in reference to the August 9, at $51500: 08 \mathrm{UTC}$ event of magnitude $\mathrm{Mw}=6.0$.

Fig 9. Cumulative number of the whole set of detected tectonic earthquakes as a function of the duration-magnitude. The duration-magnitude is calculated according to the law $\mathrm{Md}=-$ $0.87+2 * \log d+0.0035 * \mathrm{D}$, where $\mathrm{d}$ is the duration (in second) and $\mathrm{D}$ is the distance (in $\mathrm{km}$ ), a) for the whole set of data, b) for for events with epicentral distance $\mathrm{D}<100 \mathrm{~km}$.

Fig. 10. Log-log frequency-duration distribution for the 14942 volcanic tremors of duration greater than $10 \mathrm{sec}$. a) as a function of duration , b) as a function of amplitude. 
525 Fig. 11. Amplitude versus duration of the tremors.

Fig. 12. Number of tremors per day a) with relative amplitude $>10$, and b) with duration greater than $100 \mathrm{sec}$. The two main earthquakes are shown with vertical arrows.

530 Fig. 13. Daily seismic record showing different types of events and tremors. Each trace corresponds to one hour record filtered between 3-9 Hz and is drawn with the same standard scale.

Fig. 14. Time lags (min) between two successive LDTs.

Fig. 15. Time distribution of the LDTs as a function of amplitude (a) and duration (b). 


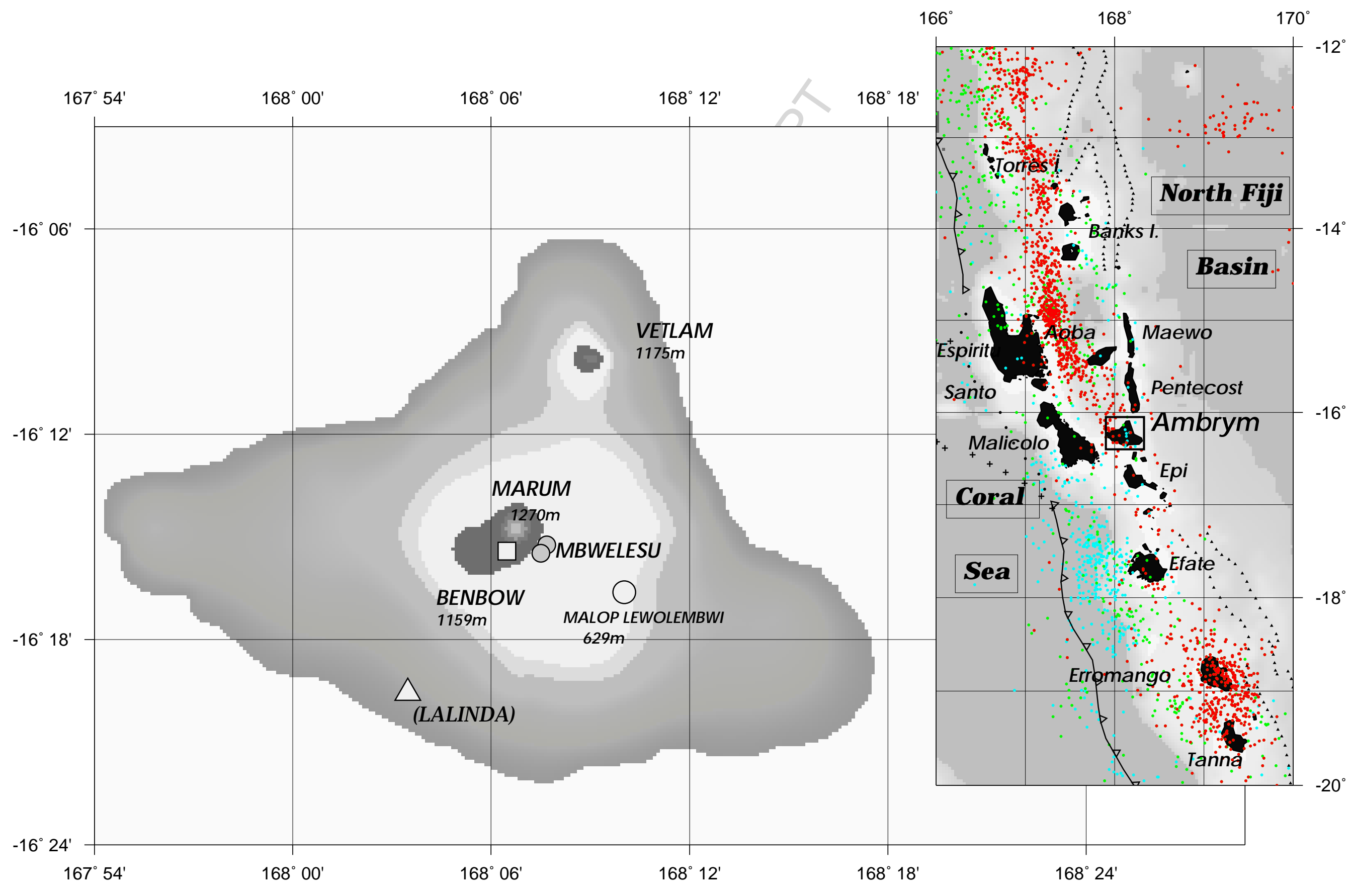




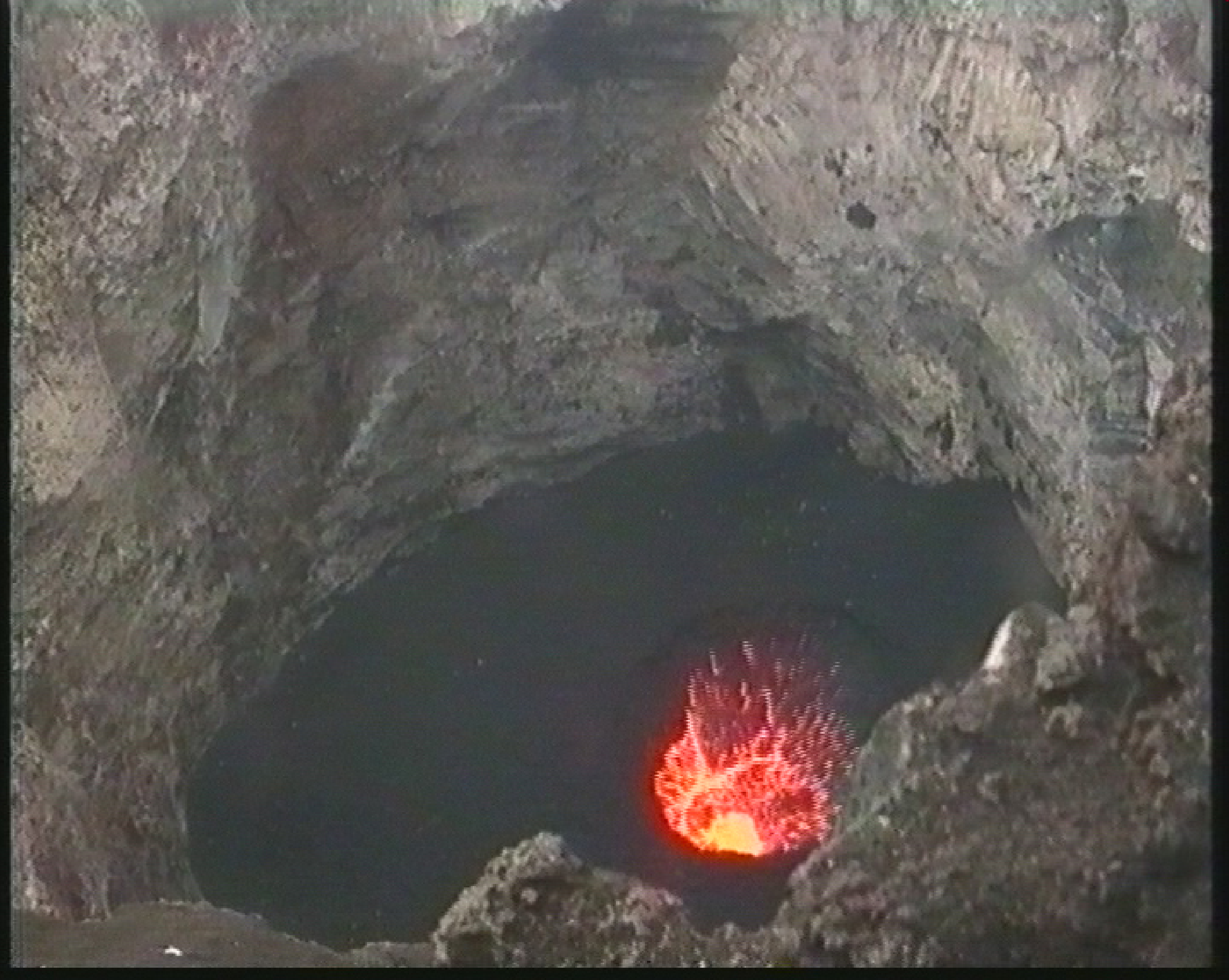



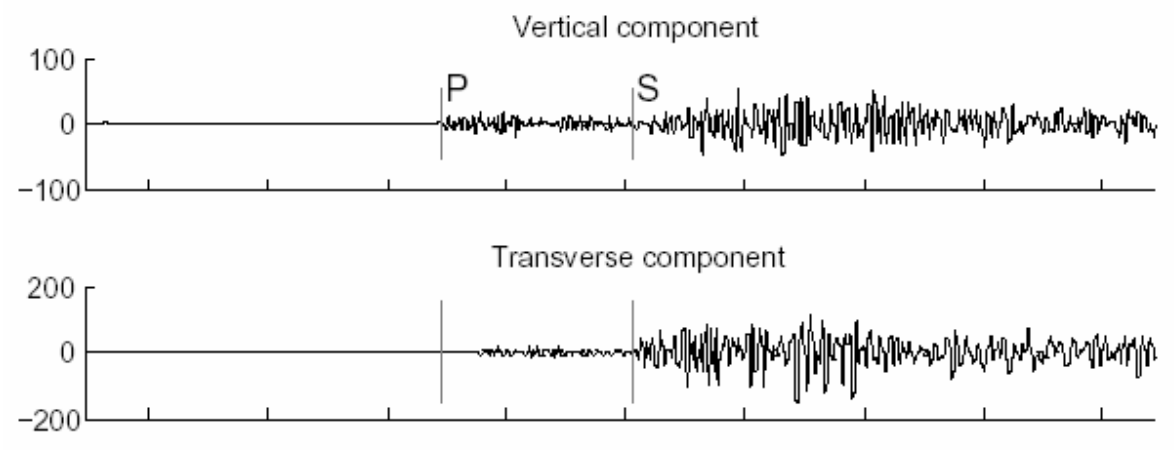

P detector: xcorr solid, SNR dashed
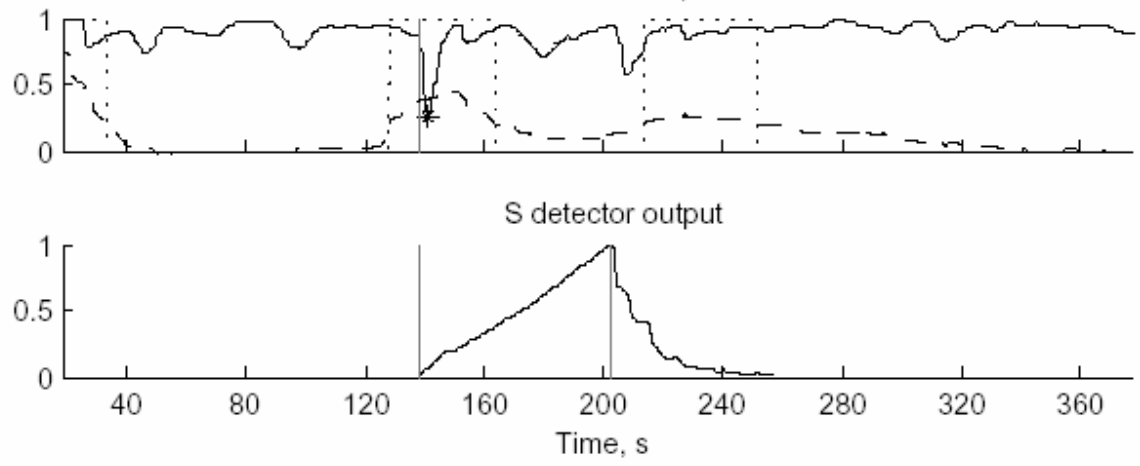


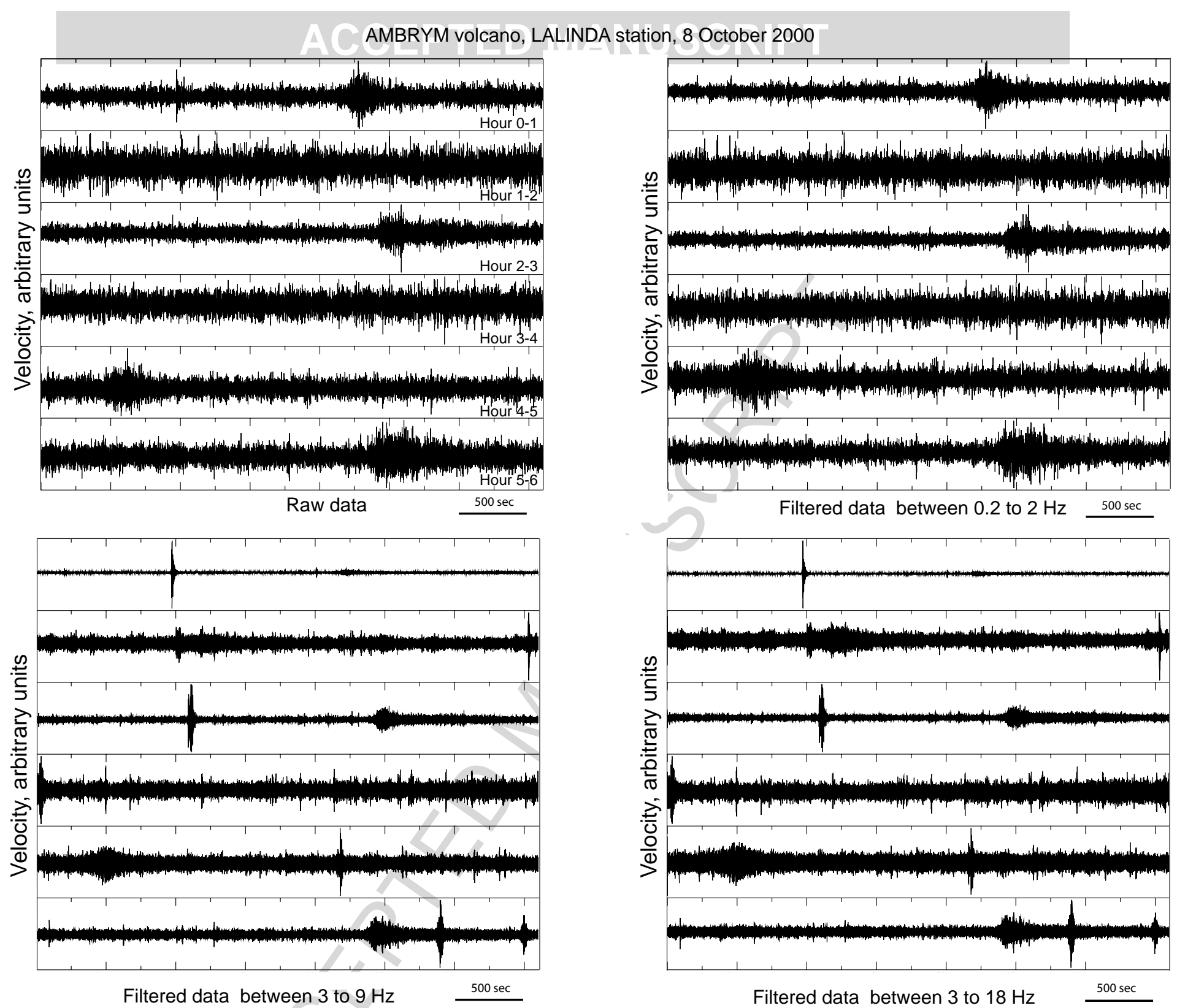




\section{AMBRYM volcano, LALINDA station, 12 August 2000}

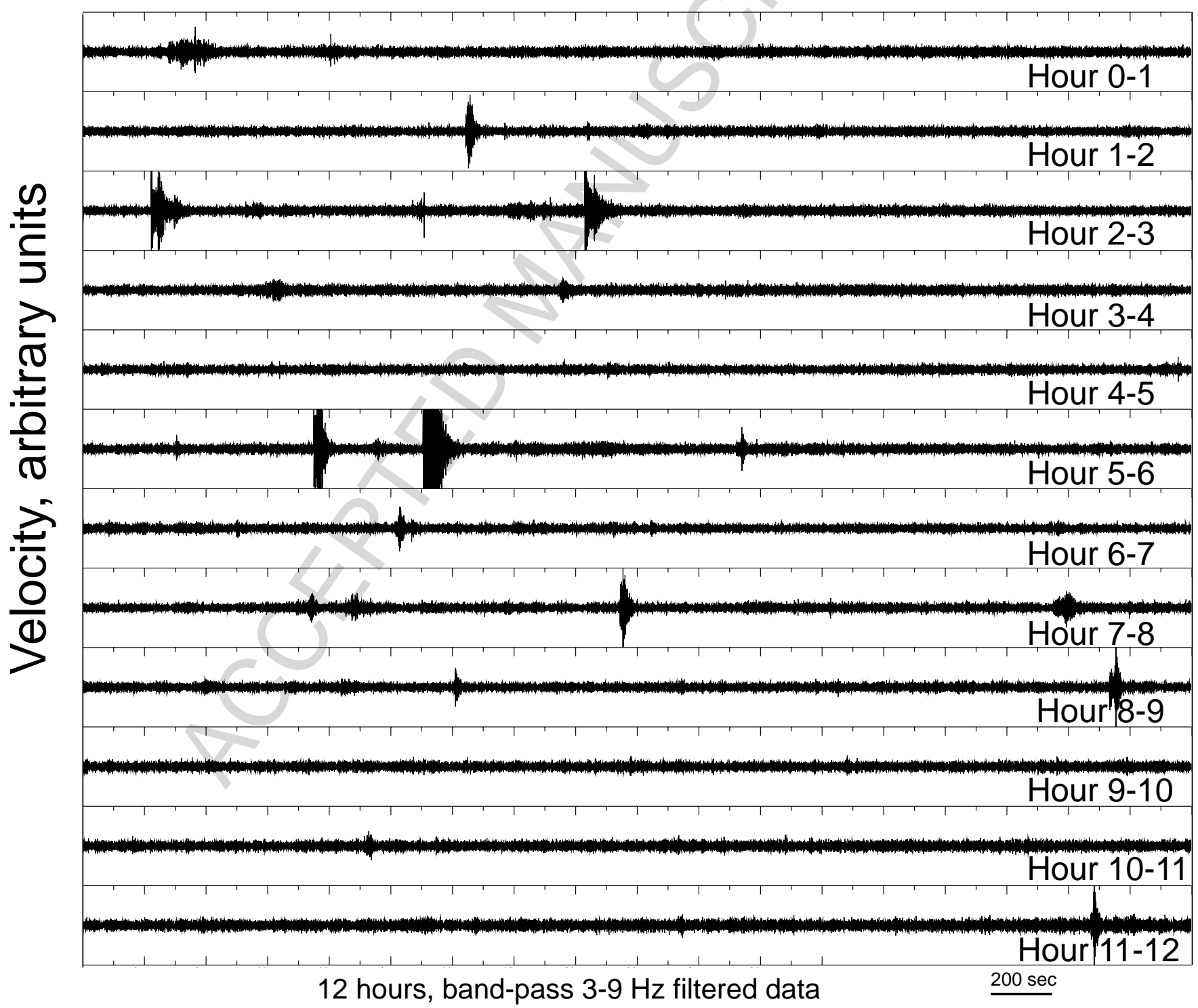


a)
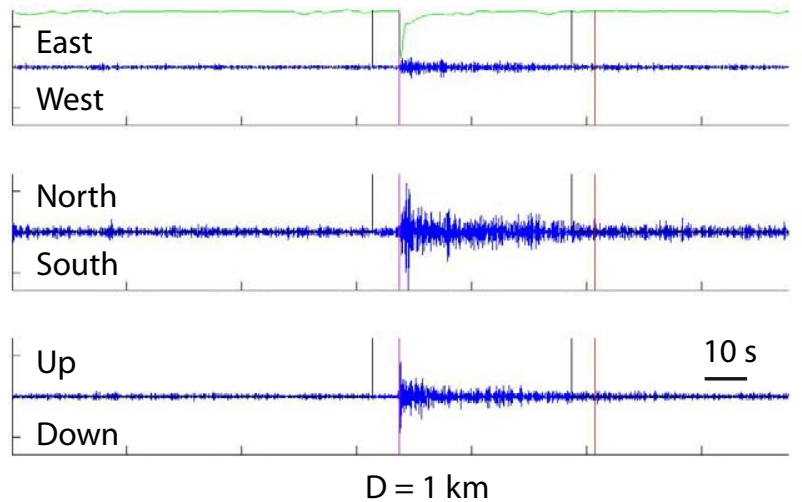

c)
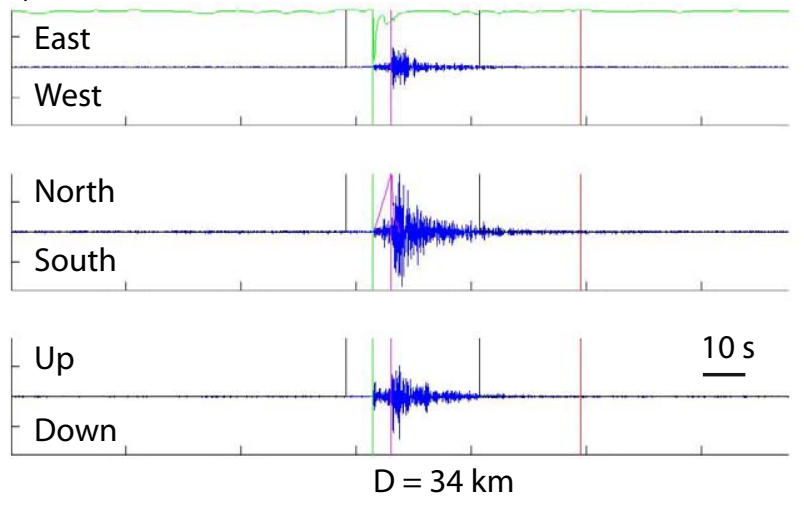

b)

2 October 2000

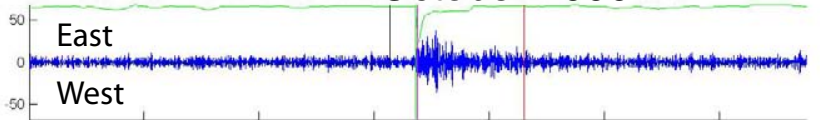
${ }_{50}^{50}$ - South

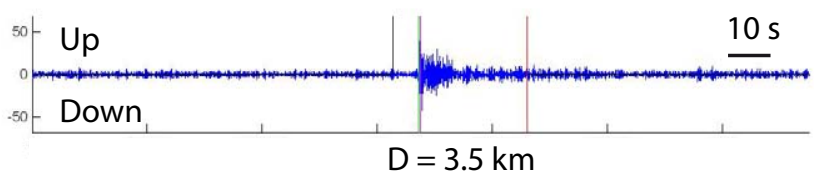

d) 4 October 2000
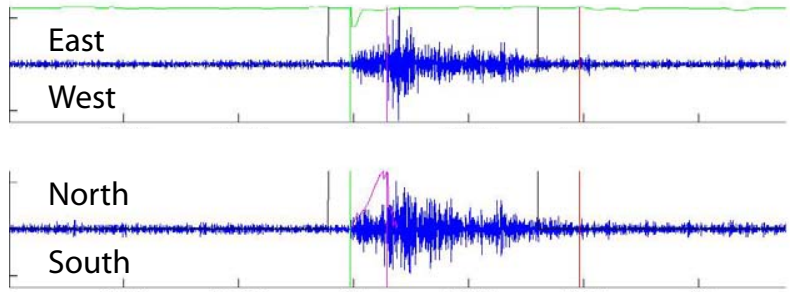

\begin{tabular}{|c|c|}
\hline Up & $10 \mathrm{~s}$ \\
\hline Down & \\
\hline
\end{tabular}




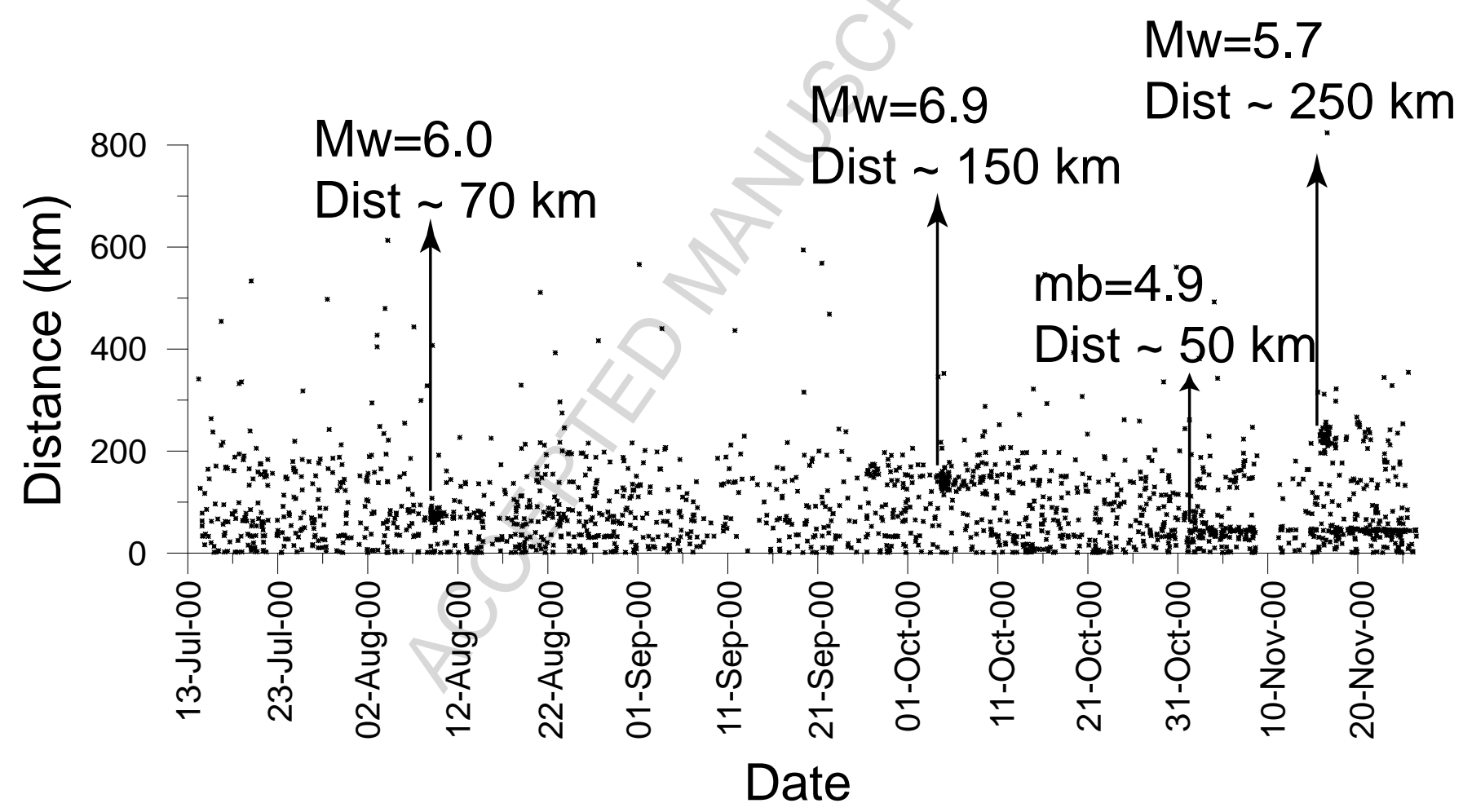




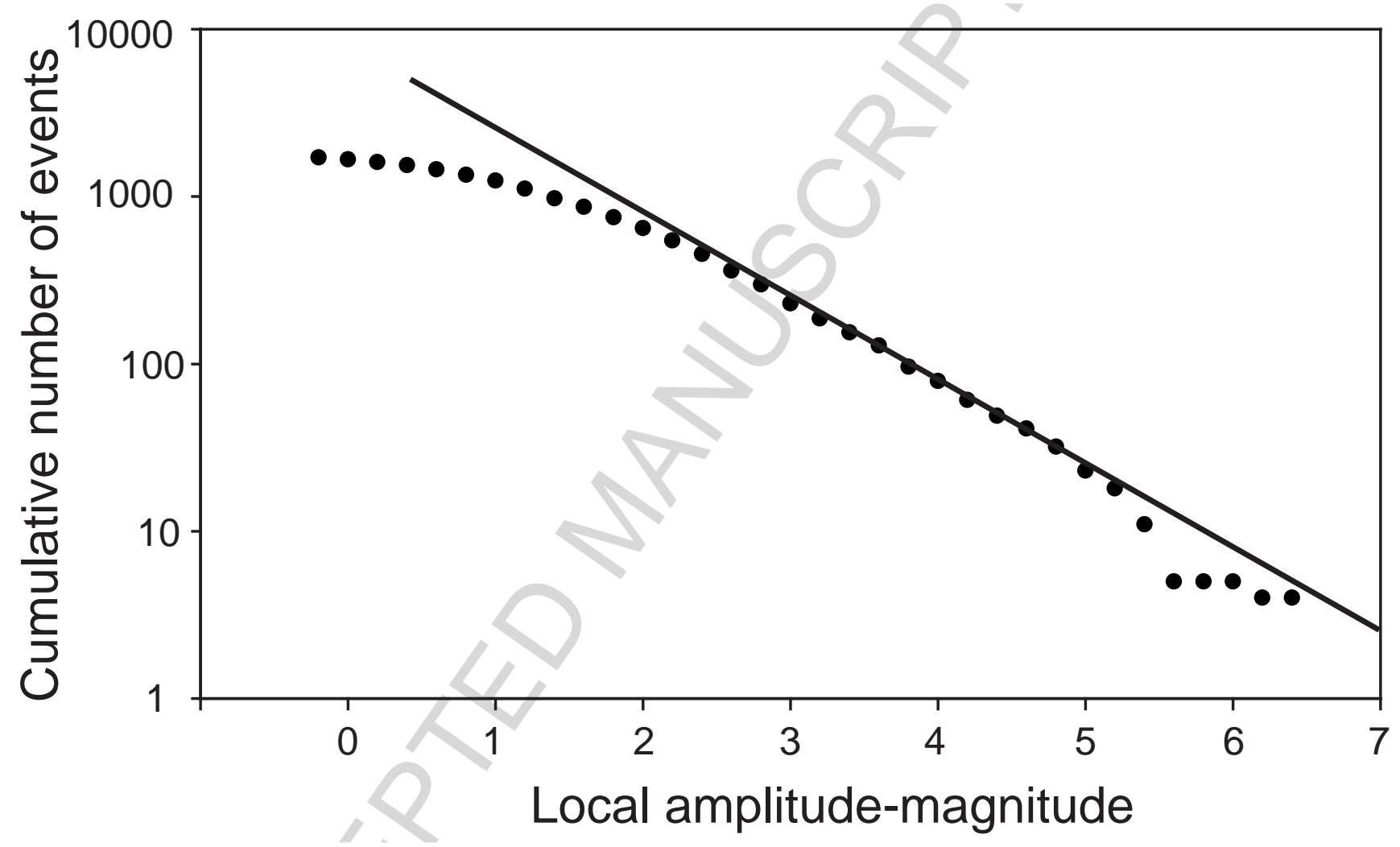




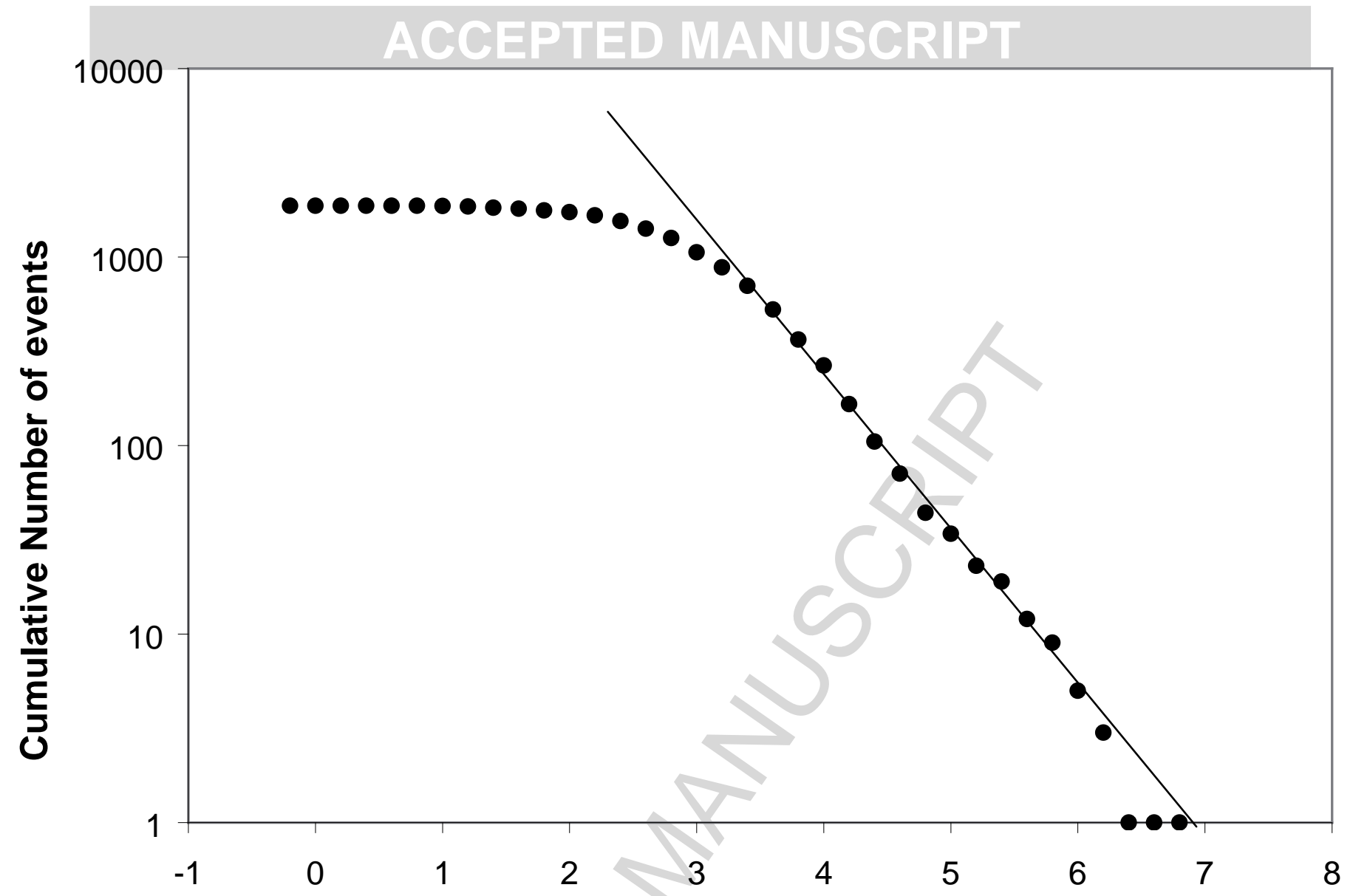

a) Local duration-magnitude

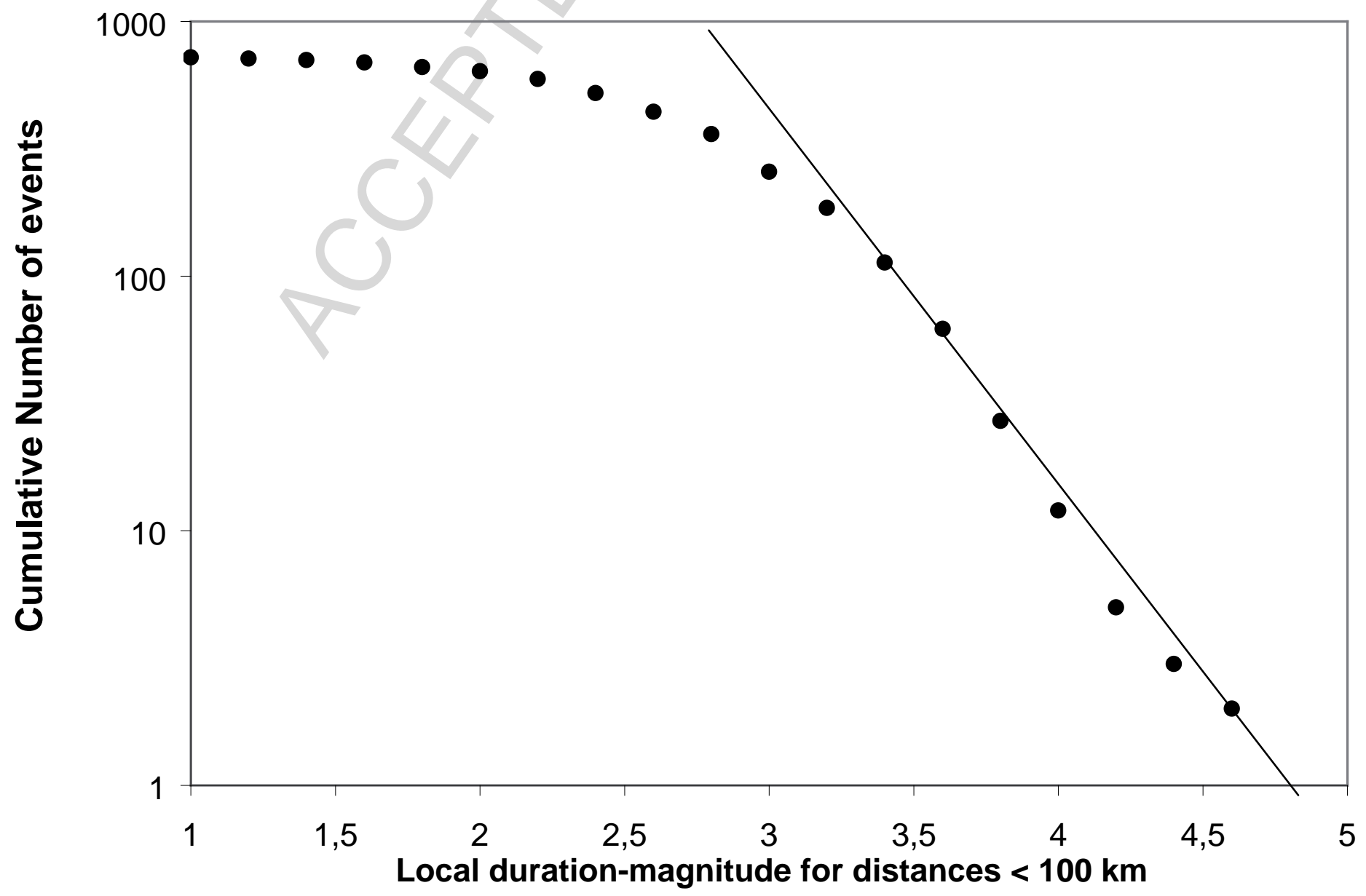

b) 


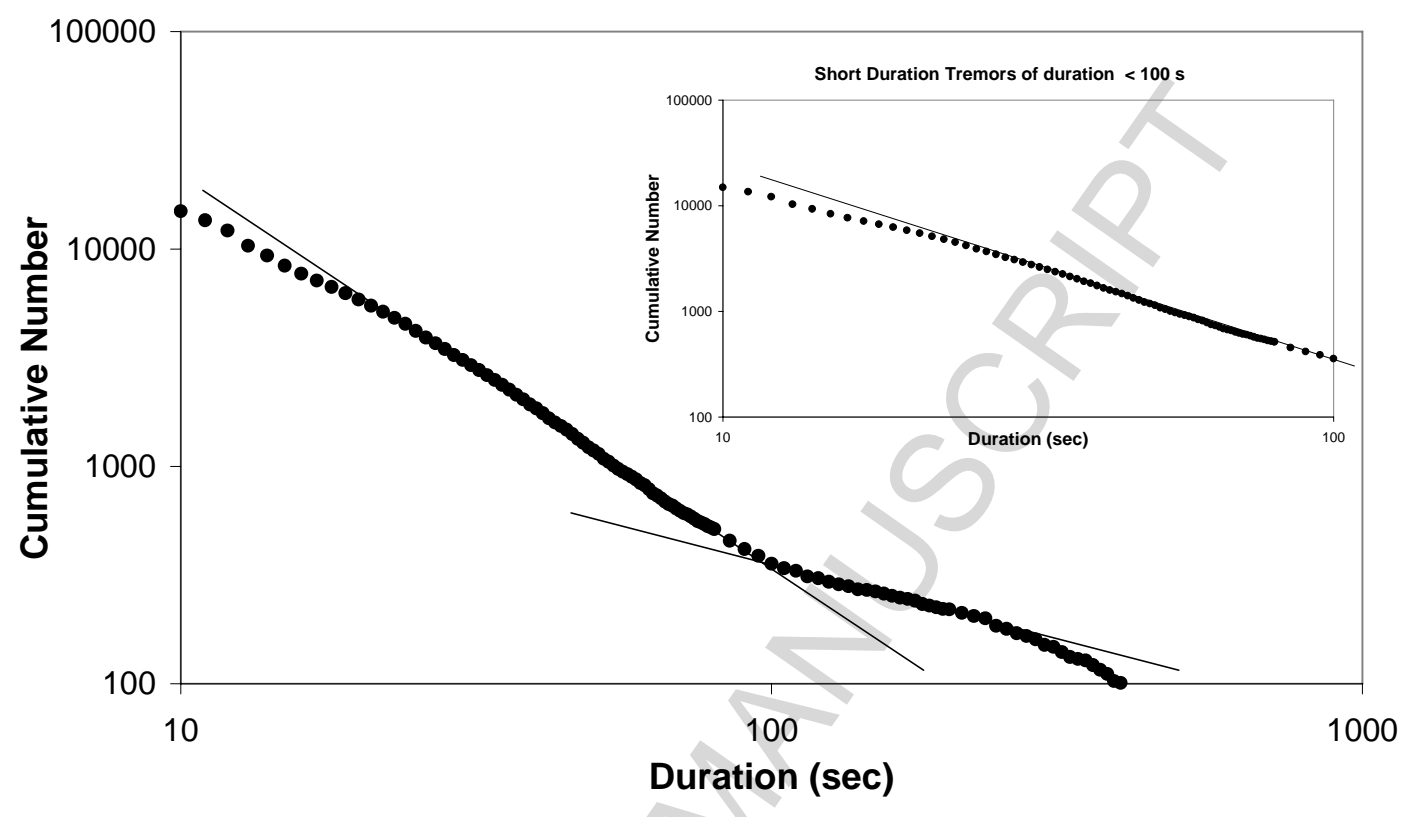




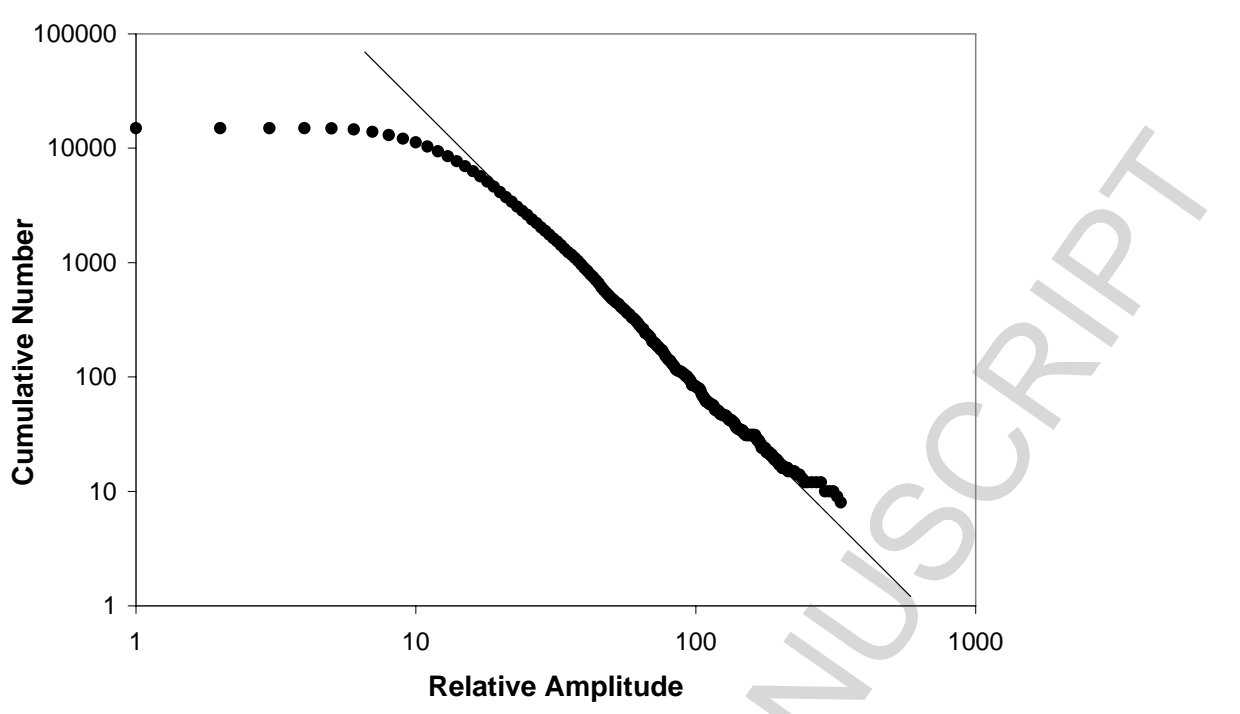




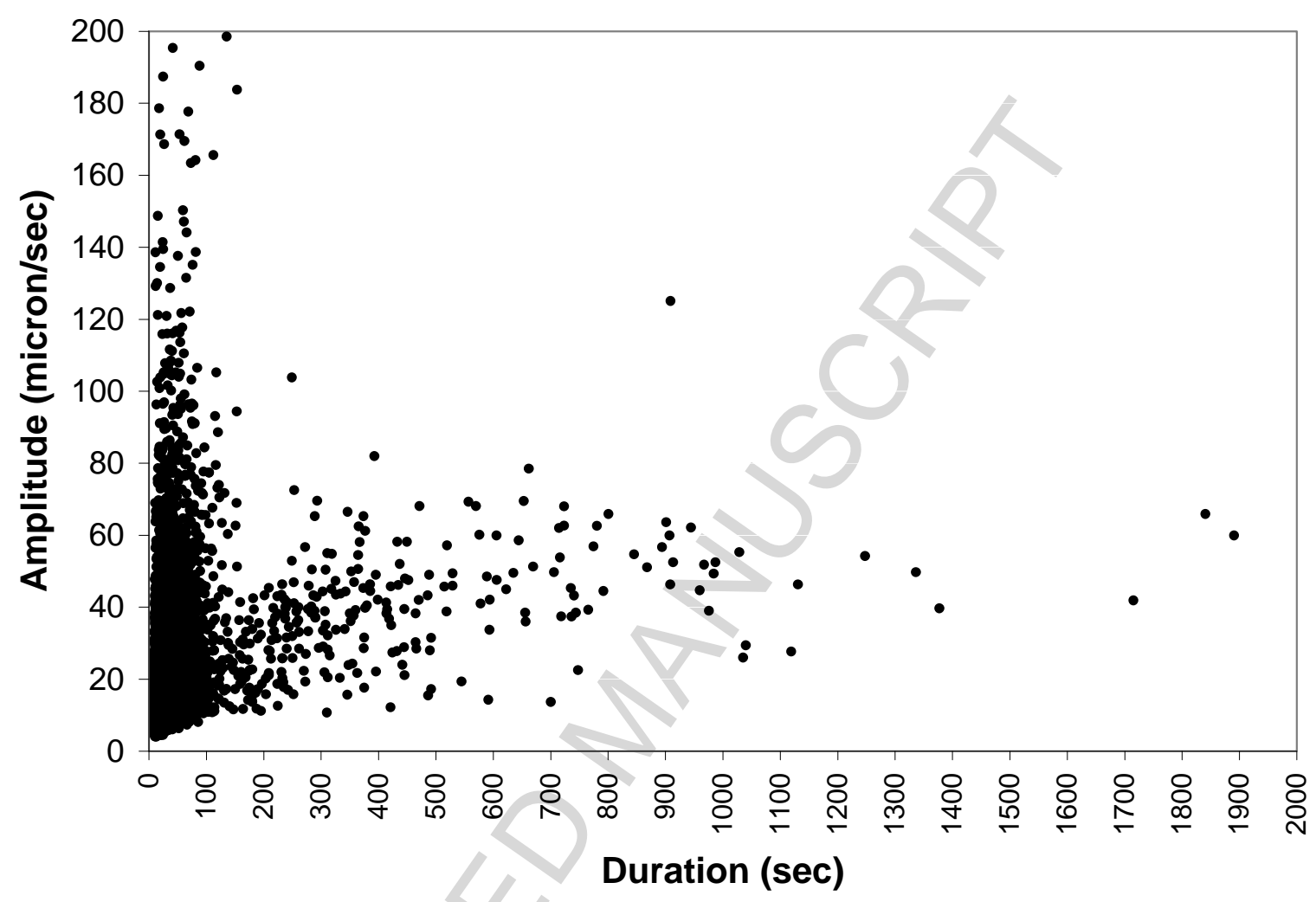



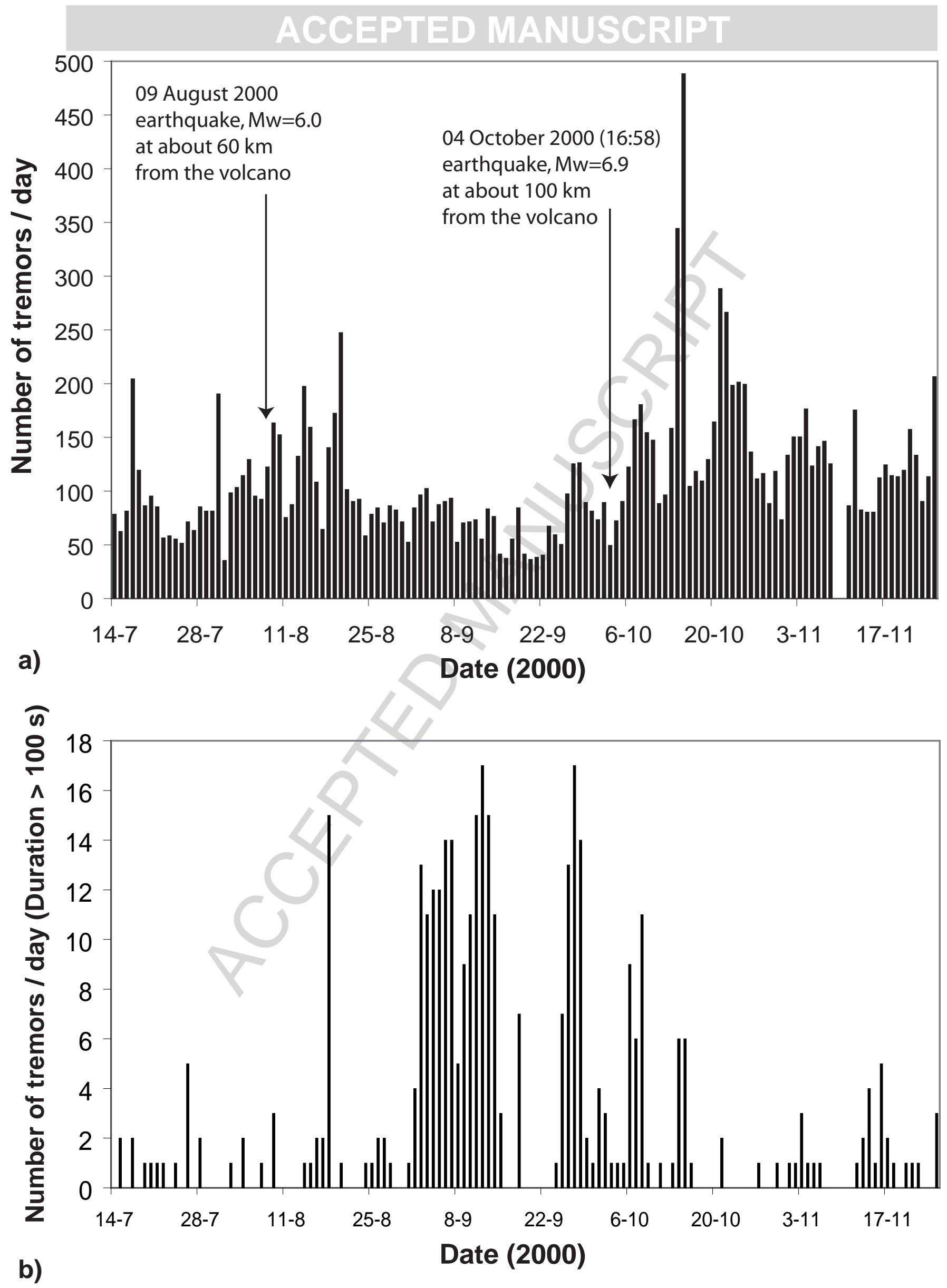


\section{AMBRYM volcano, LALINDA station, 4 September 2000}

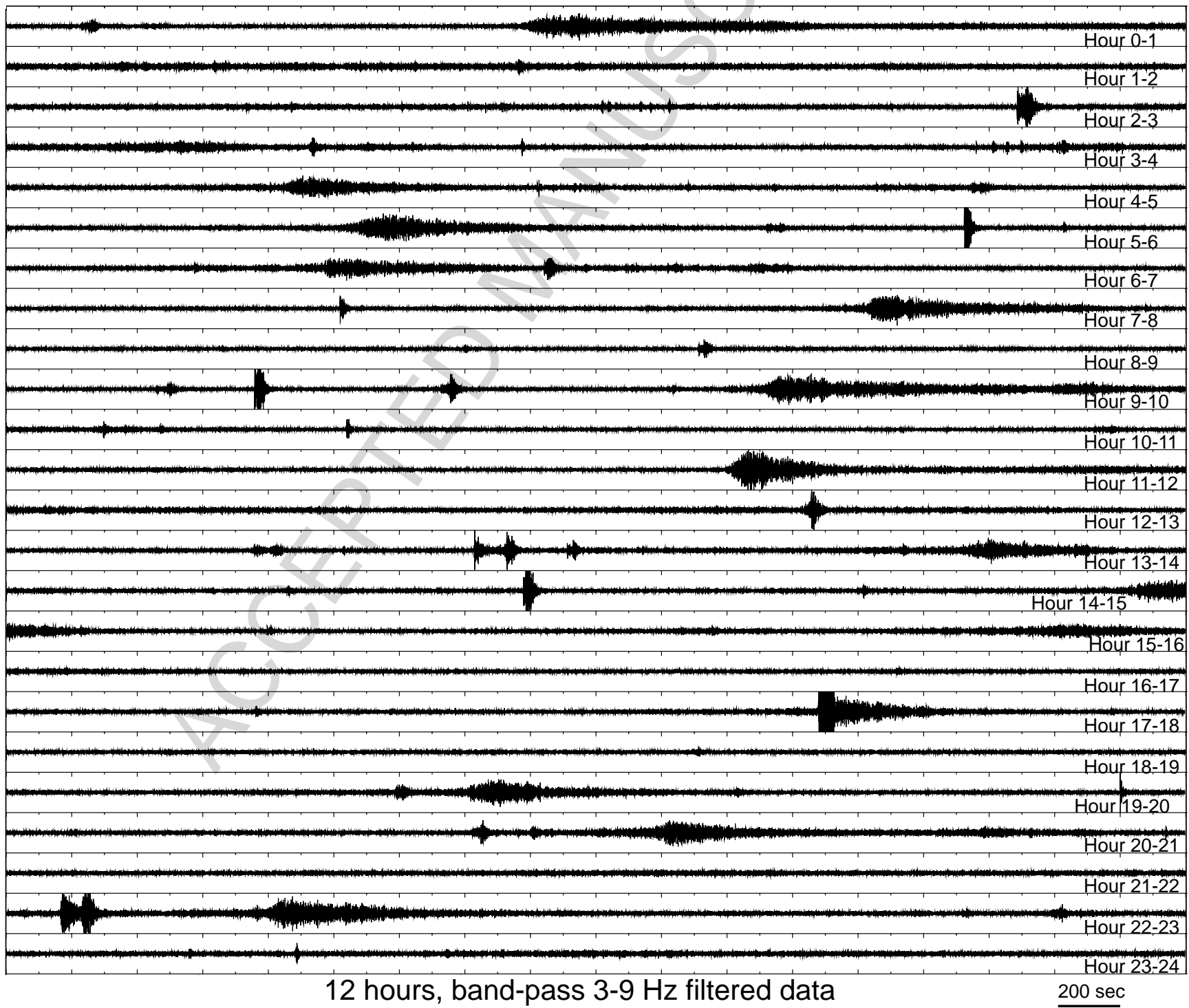




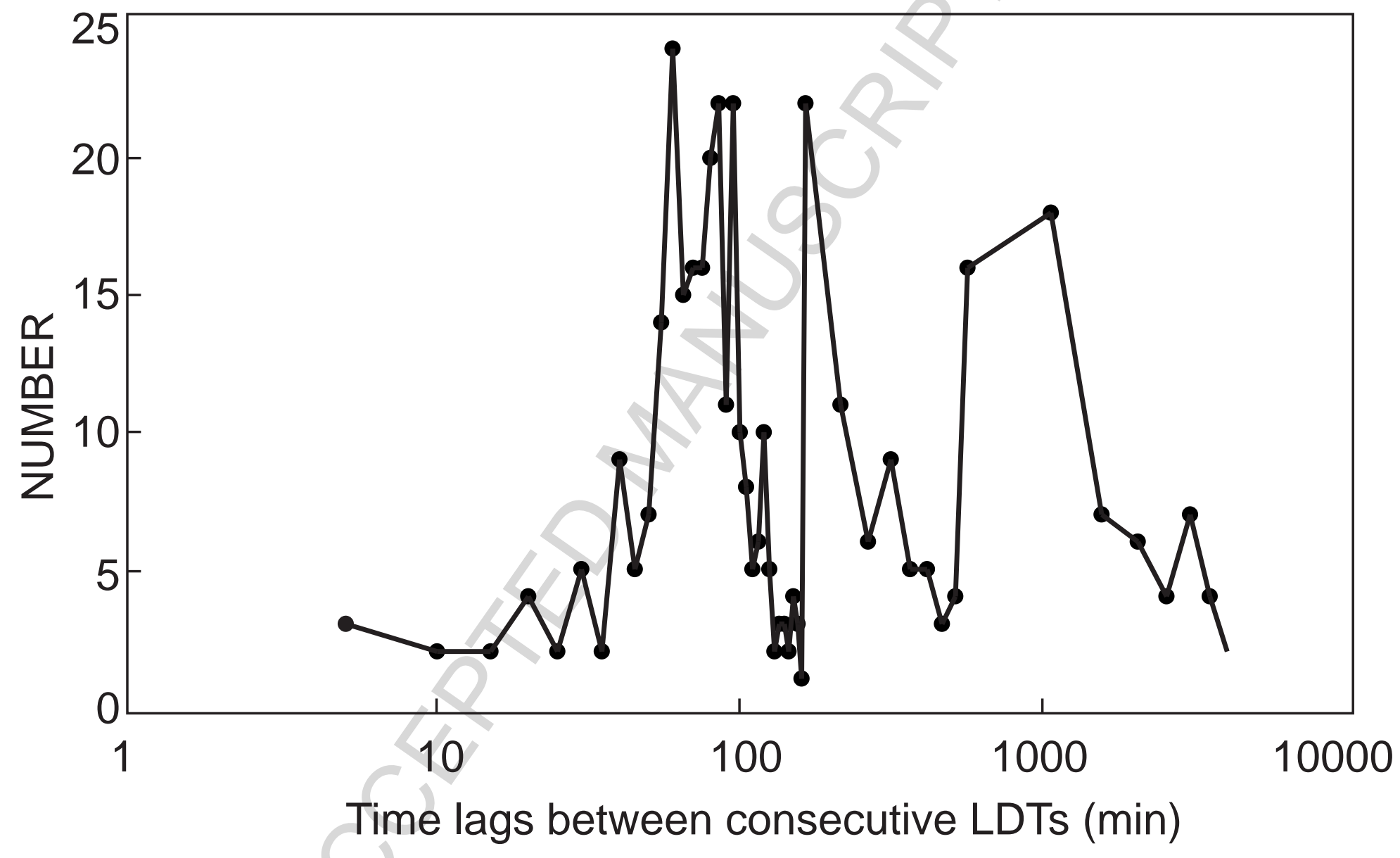



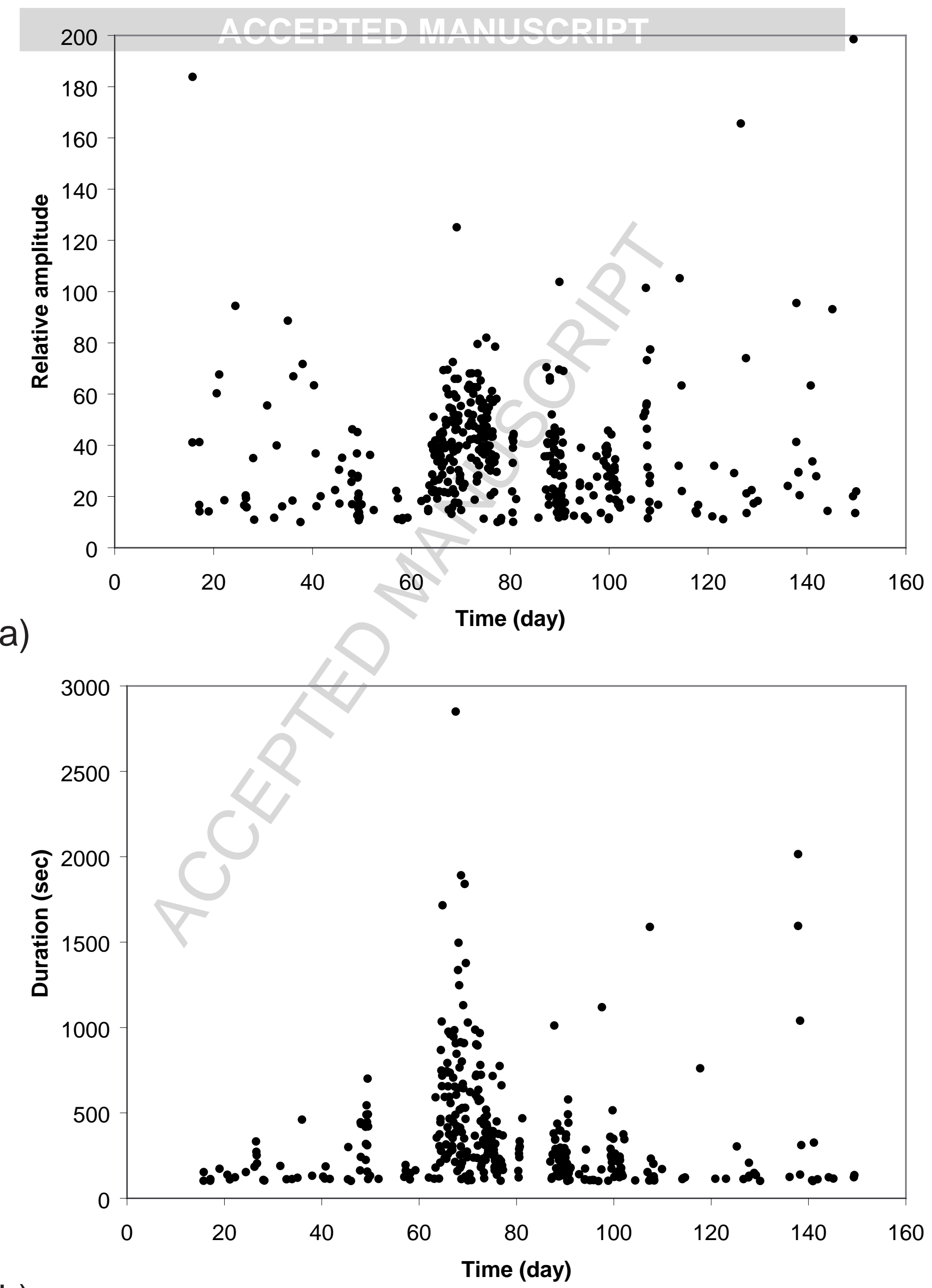

b) 